
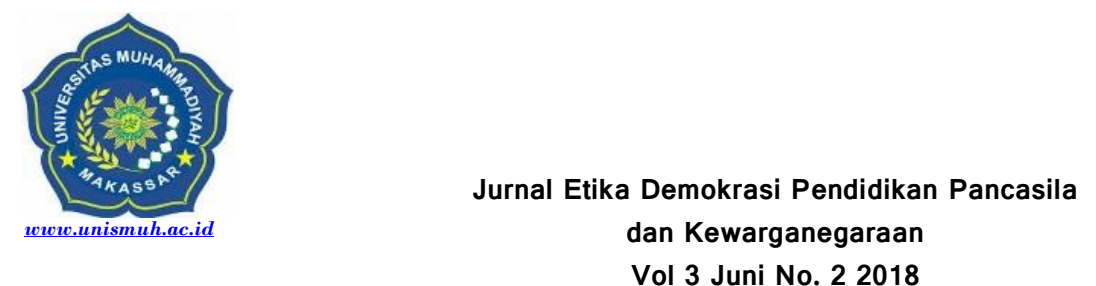

Jurnal Etika Demokrasi

\title{
Persepsi Masyarakat Terhadap Perilaku Demonstrasi Mahasiswa Universitas
}

\author{
Muhammadiyah Makassar \\ Muhajir
Pendidikan Pancasila dan Kewarganegaraan FKIP Universitas Muhammadiyah Makassar \\ muhajir@unismuh.ac.id
}

\begin{abstract}
This study aims to find out how the public perception of the demonstration behavior of unismuh students in Makassar, especially in carrying out demonstrations carried out by unismatic students of Makassar, they carried out their actions in front of the campus, namely in the street area of Sultan Alauddin Makassar, where feeling disturbed especially the Alauddin Sultan road itself is a connecting road between Gowa Regency - Makassar. This research is to find out how the response of the surrounding community is related to the demonstration carried out by unismatic students in Makassar. The type of research that is used alone is a qualitative descriptive research method, by determining the sample through purposive sampling technique by selecting several informants who have criteria that have been determined by researchers. Data collection techniques used are interview techniques, observation, and documentation. The findings of this researcher are people around the unismuh campus of Makassar, where the campus area on the alauddin Sultan road is a point of density of vehicles and the community usually uses the road. public perception of the unismuh demonstration in Makassar. The results of this study indicate that every public perception originating from the resource persons is very disadvantaged in the demonstrations of unismatic students in Makassar, because it severely disrupts their activities and creates road congestion, but many people from the community also suggest that the demonstration be delivered in front the Suldel DPRD office.
\end{abstract}

Keywords : Perception, Community Around Campus, Demonstration Behavior

Abstrak. Penelitian ini bertujuan untuk mengetahui bagaimana persepsi masyarakat terhadap perilaku demonstrasi mahasiswa unismuh Makassar, terlebih lagi dalam melakukan aksi demonstrasi yang di lakukan oleh mahasiswa unismuh Makassar, mereka melakukan aksinya di depan kampus yaitu di area jalan sultan alauddin Makassar, yang dimana dalam melakukan aksinya masyarakat sangat merasa terganggu apalagi jalan sultan alauddin sendiri merupakan jalan penghubunng antara kabupaten gowa - Makassar. Penelitian ini untuk mengetahui bagimana respon masyarakat sekitar terkait dengan aksi demonstrasi yang di lakukan oleh mahasiswa unismuh Makassar. Jenis penelitian yang di gunakan sendiri adalah metode penelitian deskriptif kualitaitif, dengan cara penentuan sampel melalui teknik Purposive Sampling dengan memilih beberapa informan yang memiliki kriteria yang telah di tentukan oleh peneliti. Teknik pengumpulan data yang di gunakan yaitu teknik wawancara, observasi, dan dokumentasi. Temuan dari peneliti ini adalah masyarakat sekitar kampus unismuh Makassar yang dimana sekitaran kampus yang berada di jalan sultan alauddin ini merupakan titik kepadatan kendaraan dan masyarakat biasanya beraktifitas menggunakan jalan tersebut, Oleh karna itu setiap kali terjadi aksi demonstrasi mahasiswa unismuh Makassar masyarakat sangat terganggu, dan memunculkan persepsi masyarakat terhadap aksi demonstrasi unismuh Makassar. Hasil penelitian ini menunjukkan bahwa setiap persepsi masyarakat yang berasal dari narasumber sangat di rugikan dalam aksi-aksi demonstrasi mahasiswa unismuh Makassar, karna sangat mengganggu aktifitas mereka dan membuat kemacetan jalan, namun banyak pula dari masyarakat menyarankan agar aksi demonstrasi tersebut langsung saja di sampaikan di depan kantor DPRD Sul-sel.

Kata kunci: Persepsi, Masyarakat Sekitar Kampus , Perilaku Demonstrasi 


\section{PENDAHULUAN}

Mahasiswa dan perubahan, kalimat ini memang sudah sangat singkron dan sudah begitu melekat untuk disandingkan menjadi elemen kata yang tidak bisa di pisahkan, hal ini karena perubahan-perubahan di negara manapun di dunia telah dilakukan oleh insan yang bernama mahasiswa. Mahasiswa sebagai insan kampus yang masih idealis serta bersikap independen merupakan penentu kemajuan masa depan sebuah bangsa. Jadi, sangat pantaslah kalau mahasiswa sebagai generasi penerus bangsa memikul tanggung jawab ini. Mahasiswa sering melakukan gerakan-gerakan ke arah perubahan untuk kemajuan bangsa serta keadilan bagi masyarakat. Hal tersebut membuat banyak kalangan menyebut mahasiswa sebagai pahlawan demokrasi.

Namun dalam beberapa tahun terakhir ini tidak semua kalangan memiliki persepsi yang sama mengenai aksi-aksi demonstrasi mahasiswa. Pemberitaan media seringkali menggiring opini masyarakat tentang pergerakan mahasiswa yang dianggap sebagian besarnya telah melenceng dari nilai-nilai idealisme mahasiwa sebagai agen perubahan (agent of change). Aksi-aksi demonstrasi mahasiswa terkadang mendapat tanggapan yang buruk dari kalangan tertentu. Seperti halnya masyarakat, para pengguna jalan, dan orang-orang yang terhubung langsung dalam suatu aksi demonstrasi yang dilakukan oleh mahasiswa, hal ini dikarenakan aksi-aksi mahasiswa yang terkadang berujung bentrok dengan aparat ataupun masyarakat setempat. Rentetan kejadian seperti itu melahirkan stigma yang negatif oleh masyarakat. Padahal baik masyarakat maupun mahasiswa samasama memiliki hubungan yang tidak terpisahkan dalam memajukan bangsa. Bagi mahasiswa, gerakan-gerakan demonstrasi dianggap sebagai bagian dari gerakan sejarah yang tidak dapat dipisahkan dalam kehidupan berbangsa. Meskipun terkadang mendapat respon yang kurang baik oleh kelompok masyarakat tertentu. Apalagi mediamedia massa yang sudah terkontaminasi oleh kepentingan politik, mahasiswa seringkali dijadikan sebagai instrument untuk mendukung langkahlangkah kalangan yang berkepentingan. Bentrok mahasiswa dengan aparat keamanan seolah menjadi celah dalam sebuah operasi yang dikendalikan penguasa hingga berdampak pada lahirnya opini yang kerap menyudutkan eksistensi mahasiswa.

Dalam hal ini demonstrasi dapat di lakukan dengan tertib dan aman, namun lagi-lagi semua itu tergantung kepada individu yang menjalankannya dan berusaha membuat ketertiban saat terlaksananya demonstrasi, demonstrasi merupakan sebuah sarana atau alat yang sangat berkaitan dengan tujuan digunakannya sarana atau alat tersebut dan cara penggunaannya. Sehingga niat atau motivasi sangat menentukan hukum demonstrasi. Ini berarti sesungguhnya aksi-aksi itu terkait dengan niat, dan sesungguhnya setiap orang akan memperoleh sesuai dengan niatnya. Demonstrasi dapat bernilai positif, dapat juga bernilai negatif. Ini artinya ketika demonstrasi itu menjunjung tinggi demokrasi, maka dipandang sebagai hal positif dan mempunyai nilai di mata masyarakat. Namun ketika demonstrasi mengabaikan demokrasi maka dipandangan masyarakat sebagai hal yang tercela/negatif. Seperti ungkapan Megawati Soekarno putri (kandidat nasionalis) yang kharismatik berfaham marhaenisme yang selalu memperjuangkan hakhak orang tertindas), mengingatkan para mahasiswa bahwa demonstrasi adalah salah satu sarana demokrasi. Artinya, demo harus berhenti manakala pendapat mereka sudah disampaikan. Demonstrasi sendiri merupakan satu di antara sekian banyak cara menyampaikan pikiran atau pendapat. Oleh karena itu patut di perhatikan bagi setiap mahasiswa yang melakukan demonstrasi agar dapat mematuhi peraturan-peraturan yang telah di tetapkan, sebagai mana kegiatan itu perlu selalu dijaga dan dipelihara agar hal ini tidak berubah menjadi sesuatu yang tidak di inginkan masyarakat. Menjadi tugas dan kewajiban kita untuk mengingatkan bahwa demonstrasi akan diakhiri ketika pandangan dan pendapat itu telah disampaikan, walau kadangkala terasa tipis batasnya tetapi patut dipahami, demonstrasi yang disertai unsur kekerasan dan pemaksaan akan 
mudah tergelincir dalam pandangan masyarakat sekitar.

\section{METODE PENELITIAN}

Jenis penelitian yang digunakan dalam penelitian ini adalah penelitian kulitatif. Para peneliti kualitatif menggunakan teori dalam penelitian untuk tujuan-tujuan yang berbeda. Pertama, dalam penelitian kualitatif, teori sering kali digunakan sebagai penjelasan atas perilaku dan sikap-sikap tertentu. Teori ini bisa jadi sempurna dengan adanya variabel-variabel, konstrukkonstruk, dan hipotesis-hipotesis penelitian. Misalnya, para ahli etnografi memanfaatkan tematema kultural atau "aspek-aspek kebudayaan" (Wolcott, 1999: 113) untuk dikaji dalam proyek penelitian, seperti kontrol sosial, bahasa, stabilitas, dan perubahan, atau organisasi sosial, seperti kontrol sosial, bahasa, stabilitas dan perubahan, atau organisasi sosial, seperti kekerabatan atau keluarga.

Kedua, para peneliti kualitatif sering kali menggunakan persfektif teoritis sebagai panduan umum untuk meneliti gender, kelas, dan ras (atau isu-isu lain mengenai kelompok-kelompok marginal). Persfektif ini biasanya digunakan dalam penelitian advokasi atau partisipatoris kualitatif dan dapat membantu peneliti untuk merancang rumusan masalah, mengumpulkan dan menganalisa data, serta membentuk call for action and change (panggilan untuk melakukan aksi dan perubahan). Peneliti-peneliti tahun 1980-an mengalami transformasi besar-besaran yang ditandai dengan munculnya persfektif-persfektif teoritis seperti ini sehingga memperluas ruang lingkup penelitian yang muncul sebelumnya.

Ketiga, dalam penelitian kualitatif, teori sering kali digunakan sebagai poin akhir penelitian. Dengan menjadikan teori sebagai poin akhir penelitian, berarti peneliti menerapkan proses penelitiannya secara induktif yang berlangsung mulai dari data, lalu ke tema-tema umum, kemudian menuju teori atau model tertentu. Keempat, beberapa penelitian kualitatif tidak menggunakan teori yang terlalu eksplisit. Kasus ini bisa saja terjadi disebabkan dua hal: (1) karena tidak ada satu pun peneliti kualitatif yang dilakukan dengan observasi yang "benar-benar murni" dan (2) karena struktur konseptual sebelumnya yang disusun dari teori dan metode tertentu telah memberikan starting point bagi keseluruhan observasi. (John W. Creswell,2010. Hal 95-97).

Teknik pengumpulan data yang digunakan dalam penelitian ini adalah kegiatan dalam analisis data dilakukan secara interaktif dan berlangsung secara berkesinambungan pada setiap tahapan penelitian sampai tuntas dengan langkah-langkah sebagai berikut :

\section{Observasi}

Observasi yaitu melakukan pengamatan secara langsung ke objek penelitian untuk melihat dari dekat kegiatan yang dilakukan. Apabila objek penelitian bersifat perilaku, tindakan manusia, dan fenomena alam, proses kerja dan penggunaan responden kecil. Observasi dapat dilakukan dengan cara partisipasi ataupun nonpartisipasi. Dalam observasi partisipasi, pengamat ikut serta dalam kegiatan yang sedang berlangsung. Pengamat ikut sebagai peserta. Dalam peserta non partisipasi pengamat tidak ikut serta dalam kegiatan, dia hanya berperan sebagai pengamat dan tidak ikut dalam kegiatan. Kedua jenis observasi ini ada kelebihan dan kekurangannya.

\section{Wawancara}

Wawancara dilakukan secara lisan dalam pertemuan tatap muka secara individual. Pedoman wawancara berisi tentang uraian penelitian yang biasanya dituangkan dalam bentuk daftar pertanyaan agar proses wawancara dapat berjalan dengan baik. Isi pertanyaan atau pernyataan bisa mencakup fakta, data, pengetahuan, konsep, pendapat, persepsi atau evaluasi responden berkenaan dengan fokus masalah atau variabelvariabel yang dikaji dalam penelitian.

\section{Dokumentasi}

Dokumentasi ditujukan untuk memperoleh data langsung dari tempat penelitian, meliputi buku-buku yang relevan, peraturan-peraturan, laporan kegiatan atau semua data yang relevan dengan penelitian yang sedang dilakukan. Dokumen merupakan catatan peristiwa yang telah 
berlalu. Dokumen bisa berbentuk tulisan, gambar atau karya-karya monumental dari seseorang. Studi dokumen merupakan pelengkap dari penggunaan metode observasi dan wawancara dalam penelitian kualitatif. Hasil penelitian juga akan semakin kredibel apabila didukung dengan foto-foto atau karya tulis akademik dan seni yang telah ada, langkah-langkah penyusunan instrumen penelitian langkah pertama yang harus dilakukan oleh peneliti adalah mengkaji secara teoritik tentang substansi yang akan diukur.

\section{Partisipatif}

Metode ini dilakukan dengan cara terjun langsung ke lapangan, baik keadaan fisik maupun perilaku yang terjadi selama berlangsungnya penelitian. Pengamatan ini mempunyai maksud bahwa pengumpulan data melibatkan interaksi sosial antara peneliti dengan subjek penelitian maupun informan dalam suatu lokasi, selama pengumpulan data berlansung harus dilakukan secara sistematis tanpa menempatkan diri sebagai peneliti.

Teknik analisis data yang dipakai penulis adalah analisis data berlangsung atau mengalir. Ada beberapa langkah-langkah yang dilakukan pada teknik analisis data tersebut yang mengumpulkan data, reduksi data, display data, dan verifikasi menarik kesimpulan. Contoh Teknik Analisis Data Penelitian Kualitatif. Setelah rangkaian data terkumpul, selanjutnya dilakukan analisis data dengan prosedur dan teknis pengolahan berikut : (1) Melakukan pemilahan dan penyusunan klasifikasi data; (2) Melakukan penyuntingan data dan pemberian kode data untuk membangun kinerja analisis data; (3) Melakukan konfirmasi data yang memerlukan verifikasi data dan pendalaman data; dan (4) Melakukan analisis data sesuai dengan konstruksi pembahasan hasil penelitian.

\section{PEMBAHASAN}

\section{Persepsi Masyarakat Terhadap Demonstrasi Mahasiswa Unismuh Makassar}

Aksi yang dilakukan oleh mahasiswa Unismuh Makassar didepan kampus sangat meresahkan dan tentu saja sangat merugikan masyarakat terutama masyarakat yang berada disekitar Kampus Unismuh Makassar, baik pengguna jalan maupun pedagang kaki lima yang berada di sekitaran kampus merasa dirugikan. kesimpulan informan dari pertanyaan yang menyatakan bahwa apakah masyarakat terganggu jika terjadi aksi demonstrasi mahasiswa Unismuh Makassar didepan kampus yaitu masyarakat tentu sangat terganggu dan sangat dirugikan oleh aksi demonstrasi tersebut mahasiswa melakukan aksi demonstrasi dijalan yang masyarakat gunakan untuk melakukan aktifitasnya sehari-hari. Masyarakat pada dasarnya memahami bahwa aksi demonstrasi yang dilakukan oleh mahasiswa itu bertujuan untuk kepentingan orang banyak. Namun perilaku demonstrasi mahasiswa yang salah dalam melakukan aksi demonstrasi dan cenderung tidak menjunjung nilai-nilai demokrasi serta mengabaikan peraturan-peraturan yang ada dapat berdampak kepada masyarakat dan merugikan masyarakat sekitar Kampus Unismuh Makassar, tentu masyarakat dalam hal ini terganggu jika terjadi aksi demonstrasi di depan Kampus Unismuh Makassar. hal apa saja yang harus diubah dalam melakukan aksi demonstrasi mahasiswa Unismuh Makassar dapat kita lihat bahwa masyarakat menginginkan agar aksi demonstrasi tersebut di ubah agar menjadi hal yang lebih positif ke depannya, seperti mengubah cara mereka berdemo dan memperhatikan peraturan-peraturan yang ada dari berbagai persepsi masyarakat tersebut semoga dapat membangun kesadaran mahasiswa itu sendiri untuk melakukan aksi demonstrasi yang menjunjung tinggi nilai-nilai demokrasi dan tidak melakukan hal-hal yang merugikan masyarakat, agar tercapaianya demonstrasi yang elegan dan bertanggung jawab. Inti dari pernyataan di atas dapat di paparkan bahwa mahasiswa harus menjadi contoh untuk demonstrasi yang cerdas karena pada hakikatnya mahasiswa merupakan pahlawan bagi masyarakat bukan malah merugikan masyarakat.

\section{Kebijakan Kampus dalam Menyikapi Demonstrasi Mahasiswa Unismuh Makassar}

Pihak kampus dalam menyikapi aksi demonstrasi mahasiswa di depan kampus Unismuh Makassar tentu akan memberikan saksi kepada 
mahasiswa yang melanggar peraturan agar memberikan efek jera kepada mahasiswa tersebut. Yang dimana persepsi dari NR yang merupakan salah satu pembina kemahasiswaan memberikan tanggapan dan jawaban yang sangat membangun dan bijaksana, semoga dari persepsi tersebut kita dapat menyadari pentingnya melaksanakan demonstrasi yang baik dan tertib, agar tidak menggangu masyarakat sekitar dan terlaksananya demonstrasi yang cerdas. Kesimpulannya adalah akan selalu ada sanksi bagi siapa saja yang melakukan aksi demonstrasi yang anarkis atau tidak sesuai dengan aturan yang ada baik dari pihak kepolisisan maupun sanksi akademis.

Hasil dari penelitian ini menujukkan bahwa persepsi masyarakat terhadap perilaku demonstrasi mahasiswa Unismuh Makassar yang di lakukan mahasiswa didepan kampus itu tidak sepenuhnya buruk namun jika dilakukan sesuai dengan aturan yang berlaku, dan masyarakat menolak jika demonstrasi dilakukan secara anarkis. Oleh karena itu masyarakat ingin mahasiswa melakukan demonstrasi secara tertib dan sesuai dengan aturan-aturan yang berlaku. Hal ini serupa dengan penelitian terdahulu yang relevan yaitu oleh Rizki Nur Aprilia Tinjauan sosiologi hukum perspektif masyarakat terhadap demonstrasi mahasiswa di Kota Makassar. Bagi mahasiswa demonstrasi adalah sebuah cara untuk menyampaikan kepada masyarakat luas tentang sebuah perjuangan politik untuk mengagas adanya perubahan perubahan sebagai wujud dari berbagai tuntunannya. Penelitian ini bertujuan untuk mengetahuai bagaimana persepktif masyarakat terhadap demonstrasi mahasiswa di Kota Makassar. Untuk mencapai tujuan tersebut penulis menggunakan teknik. Hasil dari penelitian ini menujukkan bahwa pandangan masyarakat terhadap demonstrasi yang di lakukan mahasiswa itu penting jika dilakukan sesuai dengan aturan yang berlaku, namun menolak jika demonstrasi dilakukan secara anarkis. Oleh karena itu masyarakat ingin mahasiswa melakukan demonstrasi secara tertib dan sesuai dengan aturan-aturan yang berlaku.

\section{KESIMPULAN}

Hasil dari penelitian ini menujukkan bahwa persepsi masyarakat terhadap perilaku demonstrasi mahasiswa Unismuh Makassr yang di lakukan mahasiswa didepan kampus itu tidak sepenuhnya buruk namun jika dilakukan sesuai dengan aturan yang berlaku, dan masyarakat menolak jika demonstrasi dilakukan secara anarkis. Oleh karena itu masyarakat ingin mahasiswa melakukan demonstrasi secara tertib dan sesuai dengan aturan-aturan yang berlaku. Terkait dengan bagaimna solusi kebijakan kampus dalam menyikapi demonstrasi mahasiswa Unismuh Makassar dapat dipahami bahwa demonstrasi itu diperbolehkan sepanjang tidak menggangu masyarakat dan tidak melenceng dari aturanaturan yang berlaku, dan pihak kampus juga akan memberikan sanksi tegas bagi mahasiswa yang melakukan aksi demonstrasi yang anarkis.

\section{DAFTAR PUSTAKA}

[1] Almond, Gabrial A. dan verba, Sidney, (1990) .Budaya politik, Tingkah laku politik,dan Demokrasidi lima Negara. Bina Aksa Jakarta.

[2] Arifin.M (1995) ,Pengembangan Program Pengajaran. Surabaya : Airlangga University Press.

[3] Arikunto, S. (2010). Prosedur Penelitian Suatu Pendekatan Praktik, Jakarta: PT Rineka Cipta

[4] Azwar, Saifuddi (1997). Sikap Manusia; Teori dan Pengukurannya. (Yogyakarta : Penerbit Fakultas Hukum UII.

[5] Bimo Walgito. (1994) Psikologi Sosial. (Yogyakarta : Andi Offset.

[6] Budiarjo, Miriam . (1985). Dasar-dasar Ilmu Politik, Jakarta Gramedia.

(http://www.legalitas.org/proses/UndangUndang/9April?Selasa,24april2018).

[7] Creswell W. John, (2010). Research Design: Pendekatan Kualitatif, Kuantitatif, dan Mixed. Yogyakarta: Pustaka Pelajar.

[8] David Krech, Richard S. cruthfield dan egorton L. Ballachey. (2003). Individual and Society . Jakarta: Erlangga.

[9] Dahar, Ratna Wilis. (1989).Teori-teori Belajar. (Jakarta. Erlangga.

[1] Eep Saefulloh Fatah, (1998). Catatan atas Gagalnnya Politik Orde Baru , Yogyakarta : Pustaka Pelajar,

[10] Fatah Saefulloh, (2000). Zaman Kesempatan, Agenda-Agenda Besar Demokrasi Pasca-Orde Baru Bandung: Mizan 
[11] Gerbner, George. (2004). Media Effects : Advances in Theory and Resarce Growing up with televisions : ( Coltivation Processes ). New Jersey, USA : Lawvence Erlbraum Associates, Inc.

[12] Heraty, Toety, (1980). Aku Dalam Pustaka Jaya. Hal 207 Budaya, Jakarta :

[13] Hadeli. (2006). Metode Penelitian Kependidikan. Padang: Quantum Teaching.

[14] Iskandar. (2008). Metode Penelitian dan Sosial ( Kuantitatif dan Kualitatif ). Jakarta: GP Press

[15] James E, Anderson, (1984 ). Public poice Making , (New York: I tolt, Rinehard and Winston

[16] Mayo (1994) Intervensi Komunitas dan Pengembangan Masyarakat : Sebagai Pemberdaya Masyarakat. Jakarta: Rajawali Pers.

[17] McDougall, P. P. (1989). International Versus Domestic Entrepreneurship: New Venture Strategic Behavio And Industry Structur.

[18] Mueller, J.D. (1996). Mengukur Sikap Sosial. Pegangan untuk Peneliti dan Praktisi. Jakarta: Bumi Aksara.

[19] Notoatmodjo, Soekidjo. (2007). Promosi Kesehatan dan IImu Perilaku. Jakarta: Rineka Cipta

[1] Nasution, (2003). Metode Penelitian Bisnis. Jakarta: PT. Bumi Aksara.

[1] Rakhmat, Jalaluddin. (2005). Metode Penelitian Komunikasi, Bandung : P. Remaja Rosda Karya.

[20] Sugiono, (2011) Research Design: Pendekatan Kualitatif, Kuantitatif, dan Mixed. Yogyakarta: Pustaka Pelajar.

[21] Tim Penyusun FKIP Unismuh Makassar (2014): Pedoman Penulisan Skripsi Edisi Revisi 1 FKIP Unismuh Makassar

[22] Wilkison Kenneth dkk (1991) Intervensi Komunitas dan Pengembangan Masyarakat :Sebagai Upaya Pemberdayaan Masyarakat. Jakarta: Rajawali Pers. 